\title{
APPLICATION OF THE COMPONENT METHOD TO COLUMN BASES
}

\author{
J.P. JASPART ${ }^{1}$ and D. VANDEGANS ${ }^{2}$ \\ ${ }^{1}$ Department MSM, University of Liège \\ ${ }^{2}$ CRIF Steel Construction Department \\ 6, Quai Banning, 4000 Liège, BELGIUM
}

\begin{abstract}
Column bases transfer reactions from the structure to the foundation. When subjected to normal forces, shear forces and in-plane bending moments, they deform, particularly in rotation. This rotational behaviour is usually idealized as pinned or fully rigid. But in most of the cases column bases have a high semi-rigid behaviour which influences significantly the global frame response. In this paper, a mechanical model to predict their moment-rotation response is presented. To achieve this goal, the component method described in Annex $\mathrm{J}$ of Eurocode 3 (Eurocode 3, 1994) is used and extended. According to the component method (Jaspart and Maquoi, 1994), any structural joint is considered as a set of individual components and the determination of its mechanical properties as strength and rotational stiffness includes three main steps: (i) definition of the constitutive components, (ii) evaluation of their mechanical properties and (iii) assembly of the components so to derive the joint properties. Lastly, comparisons of the mechanical model with experimental laboratory tests on column bases are performed.
\end{abstract}

\section{KEYWORDS}

Component method, column bases, experiments, mechanical model, strength, rotational stiffness, Eurocode 3.

\section{INTRODUCTION}

As said before, the semi-rigid behaviour of column bases influences the structural frame response and in particular the frame lateral deflections and the global frame stability in unbraced frames, the column stability in braced frames. Take this semi-rigid effect into account leads to significant cost savings linked to the reduction of the man power necessary to realise rigid column bases (less stiffening) or to the reduction of the column and/or beam size in case of pinned column bases.

The rotational behaviour of the column bases is known to depend on the normal force acting in the column and the loading history. Analytical formulae for strength evaluation are now available. The prediction of the rotational stiffness is however much more complex. In this paper, a mechanical model based on the 
component method and suitable for strength and stiffness evaluation is presented and comparisons with experimental tests are shown.

\section{EXPERIMENTAL TESTS}

Twelve experimental tests on unstiffened column bases with end plates have been recently carried out in Liège (Guisse, 1995). The test set-up is described in figure 1.

The profiles used for columns are HE160B made of S355 steel. Two types of joints are considered :

connections with two anchor bolts (traditionally considered as pinned);

connections with four anchor bolts (traditionally considered as rigid).

Two different thicknesses are used for the end-plates : 15 and $30 \mathrm{~mm}$.

A normal compression force $\mathrm{F}$ is first applied to the column; it remains constant during the whole test. In a second step, the bending moment is progressively increased through force $\mathrm{F} 2$. Three different values of the normal force are considered: $100 \mathrm{kN}, 400$ or $600 \mathrm{kN}$ and $1000 \mathrm{kN}$ (about 4, 15 or 23 and $38 \%$ respectively of the actual squash load of the steel profile).

All the test results are described in (Guisse, 1995). They are named as follows: PCa.b.c where $a, b$ anc $c$ represent respectively the number of anchor bolts (2 or 4), the thickness of the end-plate (15 or $30 \mathrm{~mm})$ and the value of the constant normal force in the column in $\mathrm{kNm}$.

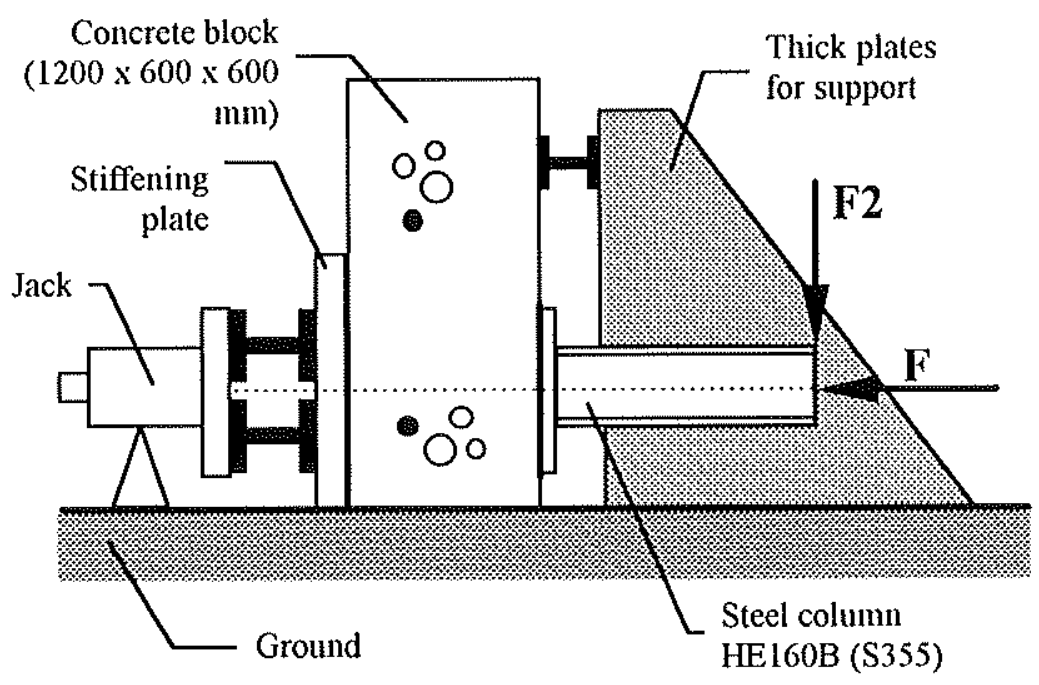

Figure 1 Test configuration

\section{MECHANICAL MODELLING}

\subsection{Generals}

The aim is to develop a model for column bases based on the component method described in Annex $J$ of Eurocode 3. First it is necessary to identify the different aspects to be covered in order to describe correctly the behaviour of column bases.

From test observations, it is seen that :

- the contact between the plate and the concrete is a complex phenomenon, which must be modelled in a very refined way; 
- the bond between the anchor bolts and the concrete quickly vanishes. Therefore it might be assumed that the anchor bolts are free to extend in tension, from the beginning of the loading;

- under the column flange in compression, the plate deforms significantly. Therefore, the pressure under the plate is far from being uniform, even under axial compression. The concept of the equivalent rigid plate to which it is referred to in EC 3 Annex L (Eurocode 3, 1992) is kept in this model;

- in the compression zone, the extended part of the plate has not to be disregarded as it prevents crushing in the concrete. The development of a plastic line is observed in the extended part during the test. This plastic line requires a large deformation energy and it is necessary to model it;

- a plastic hinge may form in the steel profile. This can lead to significant local deformations. In order to compare the mechanical model to the experimental moment-rotation curves (which include these deformations), it is imperative to take this source of deformation into account;

- the column base deforms during the loading. In particular the contact zone and the lever arm of the internal forces are changing.

Furthermore, the behaviour of each component (concrete, anchor bolts, plate, profile, ...) is non linear. Therefore only an iterative procedure allows to describe correctly the connection behaviour for the whole loading.

The mechanical model shown in figure 2 is based on these observations.

this model, the constitutive components of the column base are represented by means of extensional and rotational springs as follows (see figure 2 ):

1) extensional springs (tension or compression) for the deformation of the column end section;

2) extensional springs for the deformation of the anchor bolts and of the plate subjected to anchor bolt force. Only one spring is used for an anchor bolt row. It works only in tension;

3) extensional springs for the concrete under the plate; they work only in compression;

4) springs in bending for the plastic deformation of the plate in the compression zone(s). These springs are only activated when the extended part(s) of the plate in the compression zone(s) is subjected to contact forces with concrete.

Each of these springs is characterized by its own deformability curve, as an individual component. In general, the stiffness and resitance properties of the springs may be derived experimentally, theoretically or through specific numerical simulations. In the present work, analytical expressions have been suggested (Guisse, 1995); they allow to derive these properties on the basis of the geometrical characteristics of the components and of the mechanical characteristics of the constitutive material (steel or concrete). It has to be noted that these expressions are fully based on theoretical approaches; no curve fitting or empirical procedure has been used so to calibrate the model or to obtain a good agreement with test results. This work is briefly $r$ mmented in section 3.2 .

\subsection{Behaviour of the Individual Components}

\subsection{Concrete}

The plate-concrete contact is a very complex phenomenon, because the contact zone varies with the eccentricity of the compressive forces as well as with the flexibility of the plate, directly linked to its thickness.

The concept of equivalent rigid plate described in Annex L of Eurocode 3 is kept. The behaviour law adopted for concrete is the classical parabolic-rectangular law. The concrete-plate contact is modelled by a finite number of springs; each of them corresponds to a small part of the contact zone. A hundred of such springs leads to a good level of accuracy.

\subsubsection{Anchor bolts and plate}

The local response of the anchor bolts in tension and of the plate depends on the thickness of the plate and on the position of the bolt rows : inside or outside the flange. 
EC 3 Annex $\mathrm{J}$ is used for the determination of the behaviour curve of these components. For the end-plate deformability, it has been assumed that no prying effect occurs between the concrete and the edge of the endplate in the tension zone. This assumption is justified as follows :

- the anchor bolts have a very high deformability. Therefore the resulting relative displacement between the plate and the concrete is significant; sufficiently to be considered as higher than that due to the flexural deformation of the plate, excepted for very thin plates, but these ones are usually not used for column bases;

- the prying effects result from a concrete-to-plate contact. Even if this contact develops, the high deformability of the concrete under these concentrated forces prevents an important prying force to develop as in case of steel-to-steel contact.

In the compression part, the plate also deforms. Tests have shown that this deformation is very local and can be assimilated to a plastic hinge. This one is modelled through the use of a spring in bending characterized by an elastic-plastic law in the compression zone. This spring is infinitely rigid in the tension zone.

\subsubsection{The steel profile}

Because of the high normal forces in the column, this one might partially yield. An elastic-plastic behaviour law is adopted for the related springs.

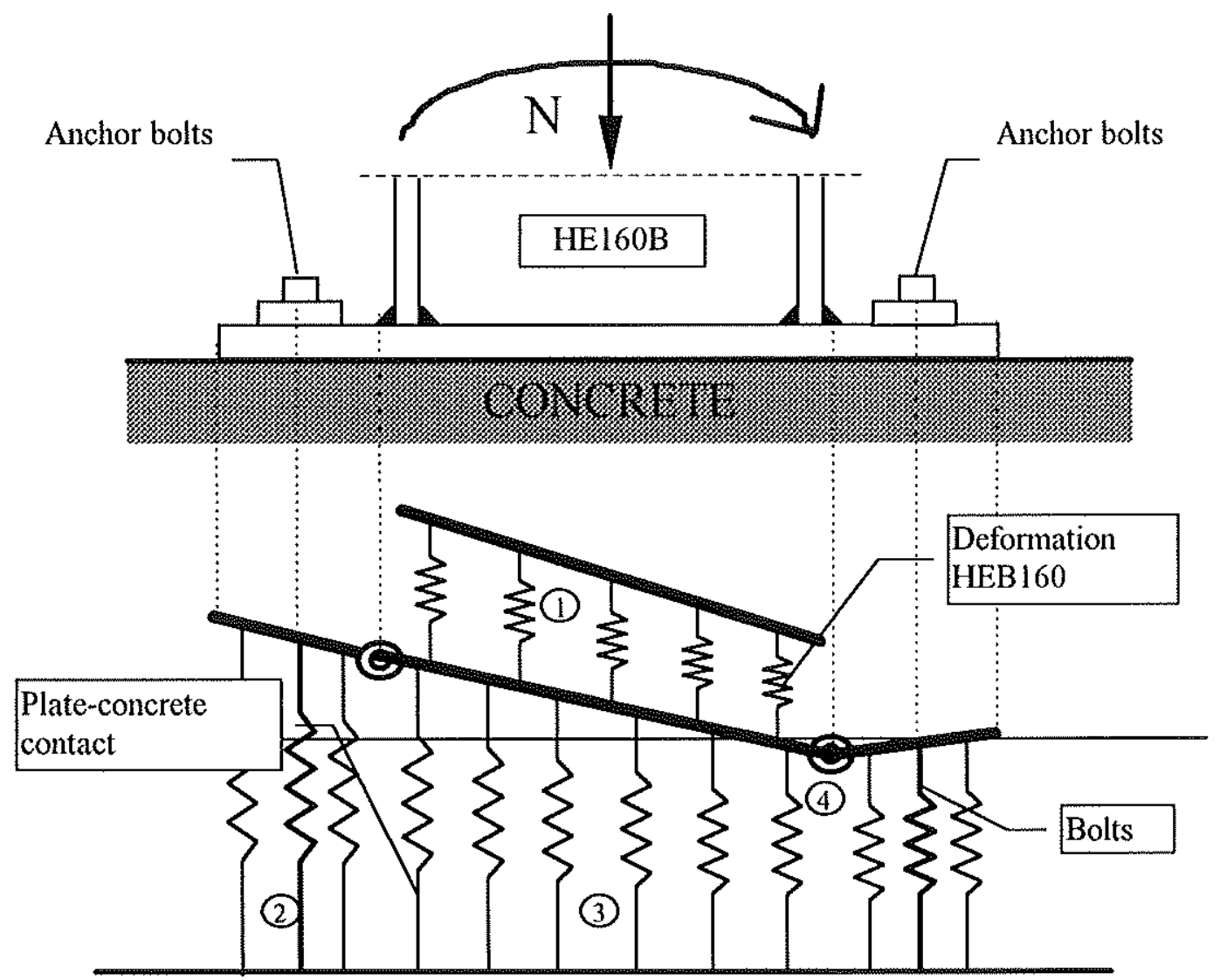

Figure 2 Modelling of the column bases

\section{COMPARISONS WITH EXPERIMENTAL TESTS}

A full comparison between the model and the experimental moment-rotation curves can be found in (Guisse, 1995). Figure 3 shows, as examples, comparisons for tests (i) PC2.15.100 and PC4.15.100 (influence of the number of anchor bolts), (ii) PC2.15.600 and PC2.30.600 (influence of the thickness of the end-plate), PC4.30.400 and PC4.30.1000 (influence of the normal force) and (iv) PC2.30.1000 and PC4.15.1000 (variation of the number of anchor bolts and of the plate thickness). The response predicted by the Penserini 
model (Penserini, 1991) is also given for tests with two anchor bolts. It has however to be said that the tests considered here are outside its normal range of validity.

The general agreement between tests and theory is seen to be quite good:

- The initial stiffness as well as the progressive yielding is rather well predicted.

- There are only small discrepancies at uitimate state (5 to $10 \%$ ). This can be explained by the quite complex behaviour at ultimate state of some of the components such as the concrete.

For test PC4.30.1000 (figure 3.c), buckling occurs in the compression flange of the column; this collapse mode has not been included in the model what explains the discrepancy between test and model.

A less good agreement has however been found for some tests:

- For tests PC2.30.100 and PC4.30.100, problems during fabrication resulted in a rather bad quality of the concrete just under the end-plate. Therefore the comparison between those tests and the model is not so satisfactory (overestimation of the stiffness and resistance properties by the model). More details are given in (Guisse, 1995).

- For tests PC4.15.400 and PC4.15.1000 (see figure 3.d), the model overestimates the mechanical properties of the column bases. The refinement of the model for what regards the definition of the contact zone between plate and concrete seems to be the way to improve the accuracy of the model.

has again to be noted that the model is a fully theoretical one and that no parameter has been adjusted so to obtain a good agreement with tests. This is likely to ensure an applicability to a wide range of situations where other profiles, anchor bolts, ratios between bolt diameter and plate thickness, ... are used.

\section{CONCLUSIONS}

Experimental tests have been carried out on column bases with two or four anchor bolts. They have shown that the column bases have a very high semi-rigid behaviour, even for so-called nominally pinned connections; this is known to be potentially beneficial when designing building frames.

A mechanical model is developed, based on the component method described in EC 3 Annex J. The nonlinear behaviour of the different components is taken into account. Therefore, only an iterative procediure allows to describe correctly the connection behaviour for the whole loading. Furthermore, with such a model, the loading history can be taken into account.

A comparison between the experimental curves and the model is given. The general accuracy is seen to be quite good, even if some small discrepancies occur at the ultimate state. Such a model is helpful in view of further investigations which would be aimed at developing a far more simple design procedure for practitioners, to be possibly included further in Eurocode 3.

\section{REFERENCES}

[1] EUROCODE 3, Revised Annex J (1994). Joints in Building Frames. European Committee for Standardization, Document CEN/TC250/SC3-N419E, Brussels.

[2] EUROCODE 3, Annex L (1992). Design of column bases. European Prenorm ENV-1993- 1-1, Brussels.

[3] Guisse S. (1995). Extending of available prediction models for moment-rotation curves to column bases (in French). Report $\mathrm{N}^{\circ} 6$, COST $\mathrm{C} 1$ research project, Dpt MSM, University of Liège.

[4] Jaspart J.P. and Maquoi R. (1994). Prediction of the semi-rigid and partial-strength properties of structural joints. Proc. of SSRC Annual Technical Session and Meeting, Lehigh, USA, pp. 172-192.

[5] Penserini P. (1991). Caractérisation et modélisation du comportement des liaisons structure métalliquefondation. Ph.D. Thesis, University Pierre and Marie Curie, Paris 6. 

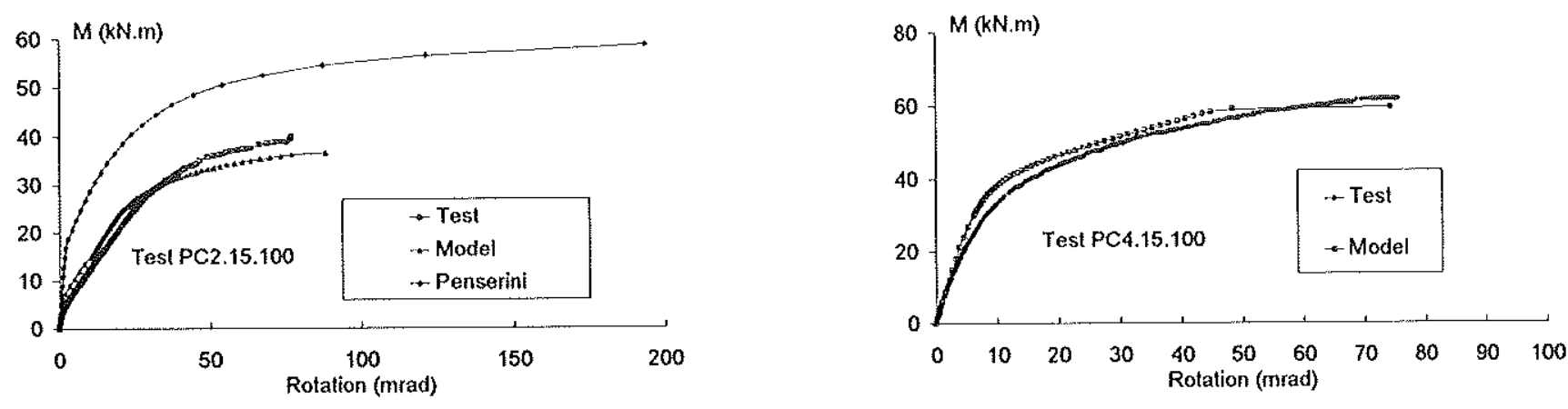

a - Influence of the number of anchor bolts
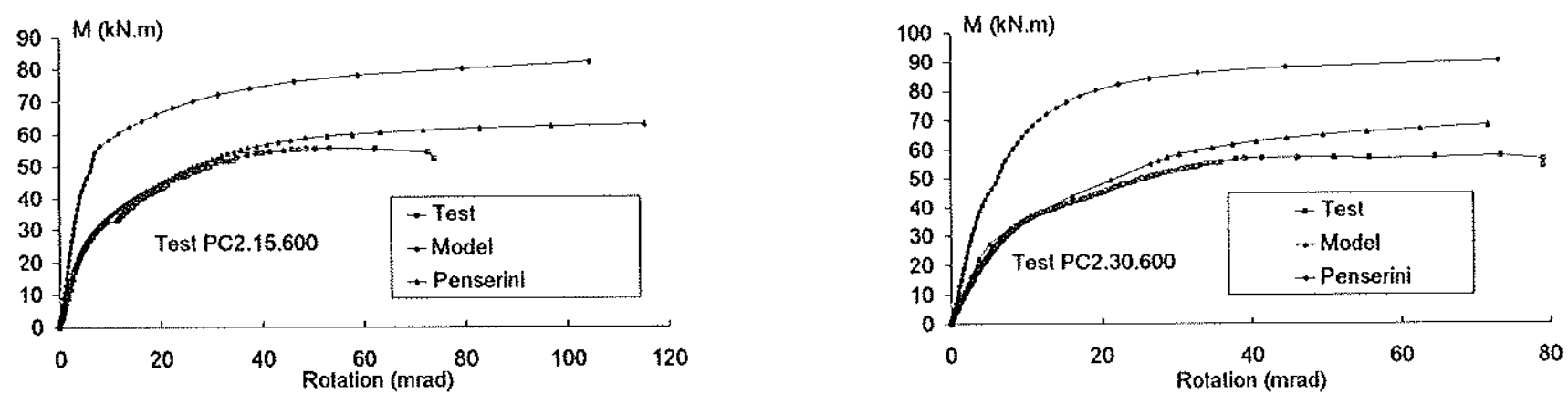

$b$ - Influence of the thickness of the base plate
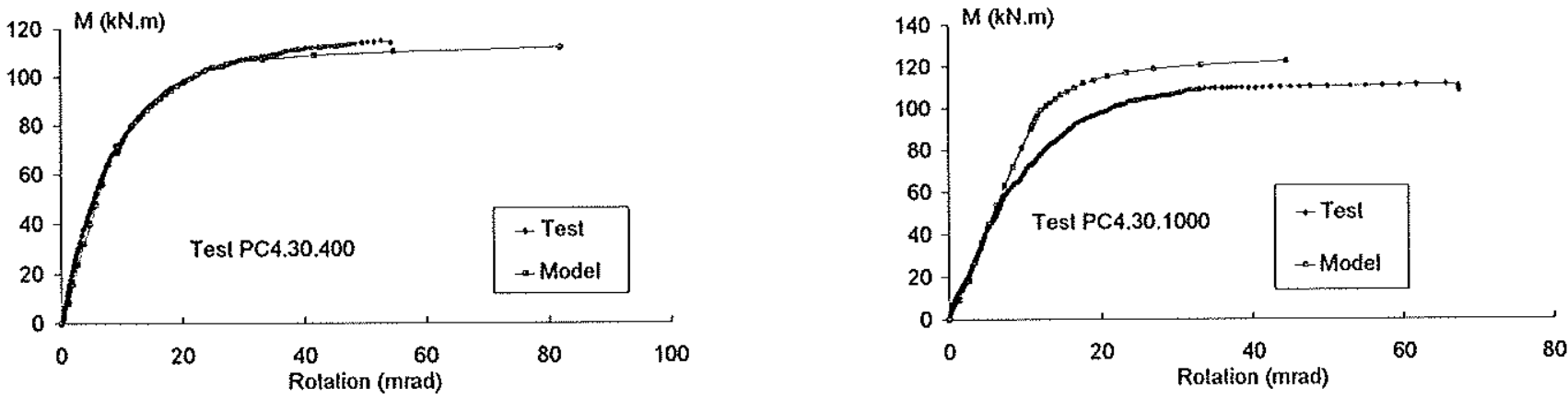

c - Influence of the normal force in the column
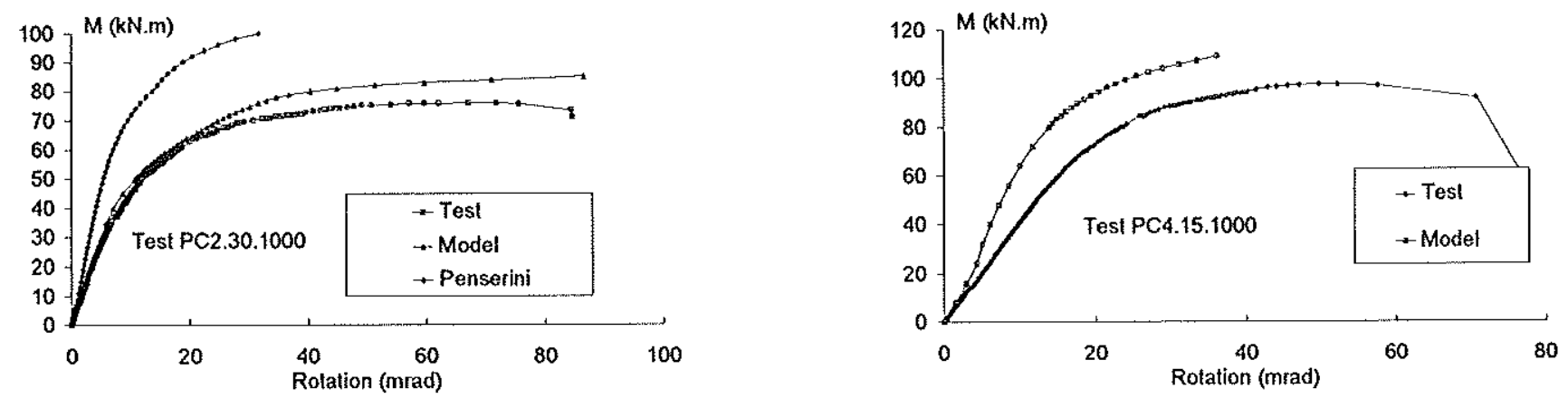

d - Variation of the plate thickness and of the number of anchor bolts

Figure 3 Comparison between the model and experimental curves 